\title{
Propylene-Styrene Multi-Block-Copolymers: Evidence for Monomer Enchainment via Opposite Insertion Regiochemistry by a Single-Site Catalyst
}

Carmine Capacchione, ${ }^{\dagger}$ Francesco De Carlo, ${ }^{\ddagger}$ Carla Zannon $\$$, Jun Okuda and Antonio Proto, ${ }^{\dagger, *}$ ${ }^{\dagger}$ Department of Chemistry, University of Salerno, via S. Allende, 84081 Baronissi (SA) Italy.

* Aristea spa, via Bosco Fili, 84091 Battipaglia (SA) Italy.

$\S$ Polimeri Europa-Istituto Donegani, via Fauser, 4 Novara Italy

${ }^{\diamond}$ Institut für Anorganische Chemie, Aachen University of Technology (RWTH), Prof.-Pirlet-Strasse 1, D-52056 Aachen, Germany

Figure S1. DSC analysis of sample 2

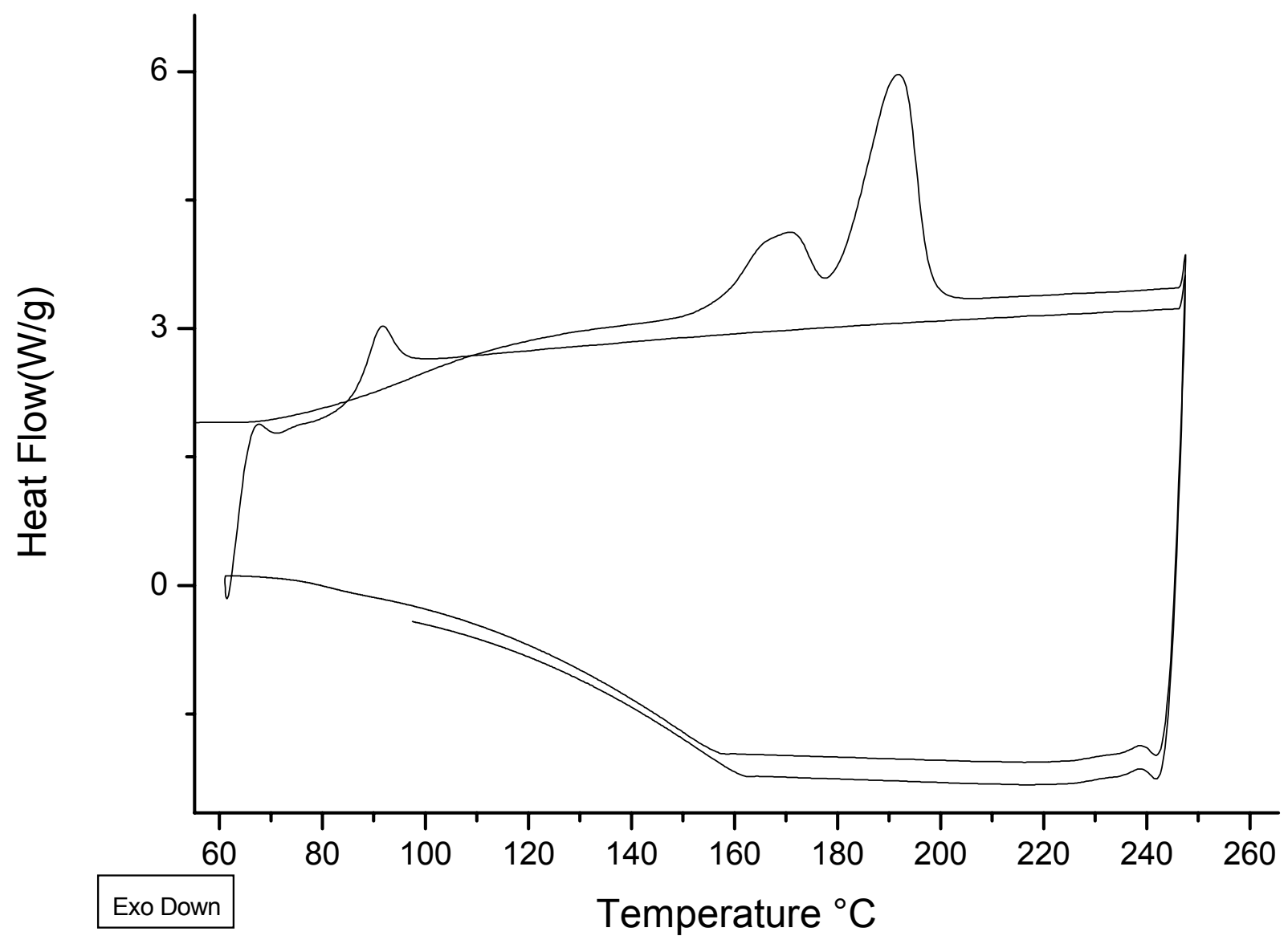

